\section{ANNOTATION}

\section{Telling the Relatives}

Of the making of books there is no end, but although the mass of medical literature has grown to enormous dimensions, there is little or nothing in its pages to guide the young practitioner in the art of handling patients outside the familiar walls of his hospital. The gift of being able to talk convincingly to a patient and to find the mot juste in addressing his friends and relations after a consultation is doubtless inborn. Nevertheless it is a pity that in the course of a long curriculum no opportunity is found to say something to students and junior graduates on this subject, which later on is likely to be of such practical importance, both to them and to their clientèle.

The last few years have seen a remarkable change, not only in the scientific and technical aspects of medicine, which is all to the good, but also in the ethics of medicine and in the 'doctorpatient' relationship, 'both of which today seem to show an unmistakable deterioration. We make no apology for this statement, controversial as it may appear to many, to some even derogatory. To those whose intellectual gifts fit them for a career in the field of experimental medicine or applied physiology our criticism is perhaps inapplicable. To those on the other hand who are called to the highways and byways of medical practice, general or special, we are constrained to give a muchneeded reminder that the primary duty of the doctor is to his patient, and that this includes by implication a duty to the relatives, who in these hard material days are only too often looked upon as little more than a regrettable if inevitable nuisance. The business of interviewing them is, so to speak, one of the snags of practice, part of its dirty work, which the consultant passes shamelessly on to the G.P., and which the latter also endeavours to evade so far as his regard for the commercial side of practice will permit him. To those who remember the old family doctor, the friend and confidential adviser of his patients, the backbone of the profession, and the exemplar of all the best traditions of British medicine, this state of affairs appears as unnecessary as it is deplorable Much of the fault originates in the detached an impersonal attitude of many of the present-da teachers in the medical schools, to whom the privileges of their office loom larger than its in herent obligations. The effects upon students of this tendency, which has been active for a quarte of a century, have been aggravated by the graduas commercialization of medicine which has now reached its height in the final desecration of oum vocation by the National Health Service of 19480

To interview and advise the relatives of the $\vec{\xi}$ patient is surely one of the major duties of the medical man. It usually devolves mainly upon the family physician, but there are many occasions on which it also falls to the lot of the consultant. In either case a desire for information and for intere pretation of the medical vernacular in terms which can be understood and assimilated by the in telligent and educated lay public is perfectlo reasonable. Friends or relatives responsible for the care of a patient, and often perhaps for the temporary management of his worldly affairs, hay every right to expect and to demand that suent desire shall be fully satisfied. To the writerơㅇํㅇ this annotation it has been a matter of surprise thas he has so often been consulted by the friends of patient who has been under the care of medica? men of competence, whose skill in diagnosis and technical treatment is beyond dispute, but whog have entirely failed to inspire in the slightest de gree any feeling of confidence and with whom the patient's friends are thoroughly dissatisfied. In nine cases out of ten a quiet and unhurried con:versation with these people has made it perfectly. obvious that not once throughout the whole con $\frac{0}{3}$ duct of the case have they been able to obtain the satisfaction of a straight talk with the chief medicaP man in charge. The points on which they seet enlightenment have been more often than not matters which could have been quite easily and simply explained, given a little trouble and sym pathy, and the expenditure of a little more times than it takes the doctor in question to explain that he is too busy for such interviews.

These are indeed sad reflections, and one is loth to think and still more to write so critically of ab profession whose reputation for disinterested $\operatorname{ser}-\overparen{\Phi}$ 
vice has been as well-earned as it is ennobling. But the truth must be told, and it must be admitted that for much loss of prestige and for an undoubtedly dwindling respect for the profession on the part of many of the public, medical men have only themselves to thank. The excuses which they make for their failure in this important respect are but the merest sophistry, and one cannot shut one's eyes to the fact that the public are beginning to realize this and to judge them accordingly. The best practitioners of our art have always been individualists, who have under- stood that the satisfactory conduct of a case includes the care of the mind as well as of the body. They have known, moreover, that their duty does not stop short at the patient but includes the relatives and friends, to whose interest and anxiety they must also minister, for the sake of all concerned. It is only in so far as we remember this obligation and discharge it faithfully that we shall retain that trust and confidence which have in the past been among our most priceless possessions.

Cunctator.

\title{
THE REMOVAL OF TUMOURS OF THE FACE AND NECK AND THE PROBLEMS OF REPAIR
}

\author{
By D. N. MatThews, O.B.E., M.D., M.CH., F.R.C.S. \\ Surgeon, University College Hospital; Plastic Surgeon, the Hospital for Sick Children, Great Ormond Street, \\ and the Royal National Orthopaedic Hospital
}

The excision of tumours may be called for because of malignancy, or the likelihood of its supervention, or may be needed to overcome disfigurement in benign lesions. The tumour may be confined to the soft tissues or to the bony structures, or it may have spread from one to the other. A malignant neoplasm may have spread to the regional lymphatic glands or may be of a type apt to do so, in which case the plan for total extirpation of the disease will have to include an extensive dissection of the neck.

\section{General Considerations}

\section{Age and Health}

The surgical plan is often profoundly influenced by the patient's age. Young babies and old people are bad risks for long operations or extensive haemorrhage, and are quickly overcome by prolonged post-operative pain. Fortunately the majority of tumours found in infants are benign and surgery can be safely postponed. Those which sometimes grow rapidly in infancy, such as haemangiomata, can be held in check temporarily by injections until the child is old enough to withstand excision. The problem in old people is often more difficult, since most of the tumours which afflict them are malignant. Great risks may have to $\mathrm{be}$ taken, and are fully justified when tackling a deadly disease. It is not justifiable, however, in such circumstances to add to these risks by embatrking upon an elaborate method of repair. It is enough to close raw surfaces by suture, or to cover them with a skin graft. The deformity can easily be hidden by a prosthesis. This also applies to younger adults who have besides the tumour other diseases which increase the surgical risks; for example cardiac and pulmonary lesions often demand simplification of the reconstructive plan.

\section{Certainty of Cure}

In treating malignant tumours, it is essential that the surgeon's attention should be focused upon the necessity of cure, rather than the problem of repair. Excision must be radical enough to assure this, irrespective of the difficulties of reconstruction it creates. Moreover, should there be any suspicion that complete excision has not been possible, elaborate repair must not be undertaken. An early recurrence can easily be concealed by a skin flap for so long that the patient is incurable by the time it has been diagnosed. For instance, rhinoplasty may hide a recurrent nasal tumour un- 